\title{
Prescription Audit with Special Emphasis on Drug- Drug Interactions Study in a Private Tertiary Care Teaching Hospital
}

\author{
Ajay Chandra ${ }^{1 *}$, C Mounica Reddy ${ }^{1}$, K Seetharami Reddy ${ }^{1}$ and Bheemachari ${ }^{2}$ \\ ${ }^{1}$ Department of Pharmacy practice, Gulbarga University, India \\ ${ }^{2}$ Department of Pharmacology, Gulbarga University, India
}

Submission: September 08, 2017; Published: September 25, 2017

*Corresponding author: Ajay Chandra, Department of Clinical Pharmacology, NET Pharmacy College, India, Tel: +977-9841103357;

Email: ajaygobinda@gmail.com

\begin{abstract}
Drug interactions (DDIs) may be defined as when two or more drugs interacting in such a manner that the effectiveness or toxicity of one or more drugs is altered. DDI in patients receiving multidrug therapy is a major concern. Although drug-drug interaction constitute only small portion of adverse drug reactions, they are often predictable and therefore avoidable or manageable. The aim of the present study was to assess the incidence and severity of DDIs in patients admitted in a tertiary care teaching hospital. A prospective, observational study was carried out for a period of 6 months. During the study period, a total of 300 prescriptions were analyzed and was found that 242 prescriptions had DDI. The average number of drugs in each prescription was 8. Regarding the severity of clinical results, the interaction was classified as minor (114), moderate (447), major (40) from the 242 prescriptions [1]. The 40 major DDI are reported from 32 prescriptions lead to increased hospitalization and health care cost of the patients. Drug-drug interaction was identified by using Micromedex 2.0®, Stockley's drug interaction book and other reputed journals. Many physicians were unaware of various drug-drug interactions. Hence education, computerized prescribing system and drug information along with collaborative drug selection and pharmaceutical care are strongly encouraged for physicians and pharmacists to avoid such incidences.
\end{abstract}

Keywords: Audit; Drug-drug interactions; Hospitalized patients; Prescription

\section{Introduction}

Drug therapy is growing more complex, thus making appropriate decision on drug therapy increasingly challenging. Drug interactions are most important in this context and proper handling of drug-drug interactions (DDIs) may prevent harmful events. DDIs are defined thus: "two or more drugs interacting in such a manner that the effectiveness or toxicity of one or more drugs is altered". DDI in patients receiving multidrug therapy is a major concern. Such interactions may lead to an increased risk of hospitalization and higher health care costs [2]. The incidence of actual occurrence of drug interactions has been reported to be much smaller, ranging from 0 to $1.3 \%$. Some studies have found that up to $11 \%$ of patients experience symptoms associated with DDIs and that DDIs are responsible for up to $2.8 \%$ of hospital admissions. Research has also shown that DDIs are associated with increased health care use. According to a recently published study, $1 \%$ of all hospital admissions are caused by DDIs, and $0.05 \%$ emergency department visits, $0.6 \%$ of the hospital admissions and $0.1 \%$ of re-hospitalizations are caused by adverse drug reactions (ADRs) due to DDIs [3]) (Table 1-4).
Table 1: Prescription statistics department wise.

\begin{tabular}{|c|c|c|}
\hline S. No. & Department & No. of Prescriptions \\
\hline 1 & General medicine & 195 \\
\hline 2 & OBG & 30 \\
\hline 3 & Paediatrics & 37 \\
\hline 4 & Orthopaedics & 17 \\
\hline 5 & Surgery & 21 \\
\hline \multicolumn{2}{|c|}{ Total } \\
\hline
\end{tabular}

Table 2: Average no. of drugs/prescription.

\begin{tabular}{|c|c|c|}
\hline S. No. & Department & $\begin{array}{c}\text { Average No. of } \\
\text { Drugs Prescribed }\end{array}$ \\
\hline 1 & General medicine & 8 \\
\hline 2 & OBG & 8 \\
\hline 3 & Paediatrics & 7 \\
\hline 4 & Orthopaedics & 7 \\
\hline 5 & Surgery & 9 \\
\hline \multicolumn{2}{|r|}{ Total } \\
\hline
\end{tabular}


Table 3: Number of drugs having NTI department wise.

\begin{tabular}{|c|c|c|}
\hline S. No. & Department & Nti Drugs \\
\hline 1 & General medicine & $\begin{array}{c}\text { 6(amikacin, gentamicin, } \\
\text { theophylline, digoxin, } \\
\text { Phenytoin, tobramycin) }\end{array}$ \\
\hline 2 & OBG & 1 (amikacin) \\
\hline 3 & Paediatrics & $\begin{array}{c}5 \text { (amikacin, gentamicin, } \\
\text { phenobarbitone, } \\
\text { phenytoin, } \\
\text { valproic acid) }\end{array}$ \\
\hline 4 & Orthopaedics & $\begin{array}{c}4 \text { (methotrexate, } \\
\text { gentamicin,lidocaine, } \\
\text { theophylline) }\end{array}$ \\
\hline 5 & Surgery & 1(amikacin) \\
\hline
\end{tabular}

Table 4: Drugs known to have potential interactions.

\begin{tabular}{|c|c|c|}
\hline S. No. & Department & Drug \\
\hline 1 & General medicine & $\begin{array}{c}\text { Ciprofloxin, theophylline, } \\
\text { gentamicin, furosemide, } \\
\text { amikacin, dexomethasone, } \\
\text { tramadole, pantoprazole }\end{array}$ \\
\hline 2 & OBG & Amikacin \\
\hline 3 & Paediatrics & $\begin{array}{c}\text { Furosemide, amikacin, } \\
\text { gentamicin }\end{array}$ \\
\hline 4 & Surgery & $\begin{array}{c}\text { Ciprofloxacin, tramadol, } \\
\text { ceftriaxone }\end{array}$ \\
\hline 5 & Orthopaedic & $\begin{array}{c}\text { Methotrexate, diclofenac, } \\
\text { pantaprazole }\end{array}$ \\
\hline
\end{tabular}

Studies conducted across the globe depict that, potential drug-drug interactions range from approximately 1 to $52 \%$. Differences in methods used, including criteria for data collection, study periods and target population, contribute to these discrepancies. Drug interactions increases with increase in number of drugs [4]. It was reported as $7 \%$ in those taking 6-10 drugs, where as it was $40 \%$ in those taking 16-20 drugs. The incidences of potential interactions have been reported up to $8.8 \%$. In USA, drug interaction incidence was reported up to $4.1 \%$. A high incidence of $47-50 \%$ of potential drug interactions were found in a study carried out in emergency department in US. The Boston Collaborative Drug Surveillance program reported 3,600 adverse drug reactions, in 10,000 patients of which $6.5 \%$ resulted from drug interactions [5]. The occurrence of drug-drug interactions in the ambulatory setting is as high as $70.3 \%$. In a retrospective review of $\mathrm{AE}$, it was noted that drug interactions accounted for $10.5 \%$ of all drug-related events which may result in patient's death if no intervention was made. Five of the ten drugs removed from the US market between 1998 and 2001 were removed because of significant drug-drug interactions. A retrospective study found that drug interactions increased from $34 \%$ among patients taking two medications to $82 \%$ in patients taking seven or more medicines [6].
Exhaustive literature survey revealed that different categories of drugs that are often used in hospitals for one or other reason have been reported to cause drug-drug interactions of different severities. Hence the scope of the present study is much broad since most of the documented drugs reported for drug interactions in the literature review are also used in our hospital setting [7]. Based on authentic data generated out of drug interaction studies conducted either on animal models or human volunteers the present study provides the scope to audit the prescriptions generated from different departments for evaluation of possible drug-drug interactions. This may help in formulating specific guidelines for rational use of drug combinations in tertiary care teaching hospital set up [8].

\section{Definition and domains}

Prescription audit: Prescription audit is a systematic scientific methodology of meta-analysis of prescriptions generated from a hospital for verification of drug related issues such as suitability of the dose with regard to age, sex, body weight, physiological conditions, presence of other diseases, diet, personal habits etc., route of administration, check for probabilities to cause adverse drug reactions (ADRs), drug-drug interactions or drug-food interactions.

Drug Interactions: Drug interactions may be defined as alteration in the Pharmacodynamic and pharmacokinetics of one or more drugs, when they are used concomitantly.

\section{Method and Methodology}

\section{Study design}

Prospective-descriptive crosses sectional study.

\section{Sample size}

300 patients.

\section{Study period}

Six month period.

\section{Study site}

The study was conducted in the various departments of Navodaya Medical College Hospital and Research Centre, Raichur, Karnataka, India, after obtaining the ethical clearance.

\section{Study criteria}
a) Inclusion criteria
A. Patients of either sex
B. Age group between 0 to 80 years
C. Non-smoker
D. Non alcoholic
E. Non tobacco chewer
b) Exclusion criteria 
A. Outpatients (Since acute polypharmacy will not produce any considerable clinical impact on drug's either pharmacokinetics or pharmacodynamics)

B. Patients with known history of allergies to a specific class of drugs

C. Patients with history of major organ system diseases like liver and kidney

D. Patients engaged recently in pesticide/insecticide spraying.

\section{Source of data}

The data was collected from various sources such as patient's case reports, laboratory data, treatment charts and patient interview/patient care taker interview using specially designed data collection form.

\section{Procedure}

A total of 300 prescriptions written by qualified medical doctors were observed and collected randomly from the wards and analyzed. Prospective data from patient prescriptions were obtained with regard to age, past medical and medication history and drugs prescribed. Latest edition of CIMS drug manual and internet source were used to decode brand name of drugs to generic names for the purpose of analysis. All information on the record were noted and captured into the personal computer [9]. Data were coded, checked for completeness and consistency. The data collected from all the prescriptions were evaluated using Micromedex $2.0 ®$ software and information regarding the number of drug-drug interactions in a prescription, their severity and management are summarized.

The accumulated data was then analyzed to measure the severity of drug interactions. The findings of the study are limited due to the availability of complete information recorded on the patents' case notes. Such missing information would have some influence on the parameters estimated. For descriptive statistics, results were expressed in terms of percentages and presented using tables according to the types of tool used.

\section{Result and Discussion}

The present study highlights the detection of DDI prevalence using Micromedex 2.0@ software, various journals, DI textbooks etc. to check prescriptions for inpatient in a tertiary care private teaching hospital. In this study, almost $80.65 \%$ of the prescriptions presented with DDI. This prevalence was higher than others found in similar studies [10]. This discrepancy could have occurred because of the different designs of the studies. Possible causes of this difference in DDI prevalence may be due to aspects related to population, year and period of study, the sequence of action and decisions used to provide drug therapy, hospital pharmacist's work and electronic drug information availability in hospital. Several DDI were detected in most of the prescriptions of our sample (Figure $1 \& 2$ ).

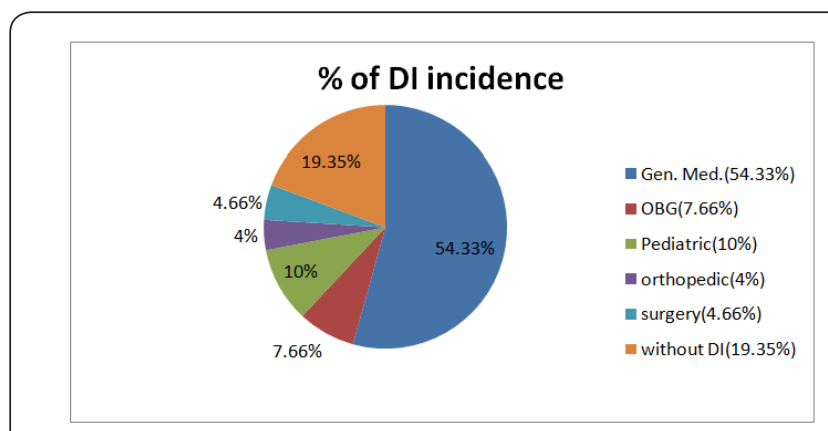

Figure 1: Percentage of DI incidence.



Figure 2: Gender wise distribution of prescriptions.

In our study, 242 prescriptions (88.65\% from 300) presented with DDI, and 40 of them (16.53\% of the 242 ) were expected to have major clinical consequences (Table 5). Most of the patients with major DDI at prescription perhaps would have presented expected drug reaction during hospitalization time. To avoid such reactions we made an early discussion with the senior physician, but our team had to return just listening to the physicians claim without any scope for rational debate. Indian healthcare system is being dominated by the doctors since generations. So, pharmaceutical care intervention in the interest of patients is a challenge and revolution.

Table 5: Severity of drug interaction.

\begin{tabular}{|c|c|c|c|c|c|}
\hline S. No. & Department & Major & Major & Minor & $\begin{array}{c}\text { Prescription } \\
\text { Without DI }\end{array}$ \\
\hline 1 & $\begin{array}{c}\text { General } \\
\text { medicine }\end{array}$ & 34 & 372 & 61 & 32 \\
\hline 2 & OBG & 0 & 28 & 11 & 7 \\
\hline 3 & Paediatrics & 3 & 44 & 13 & 7 \\
\hline 4 & Surgery & 2 & 18 & 14 & 7 \\
\hline 5 & Orthopaedic & 1 & 13 & 15 & 5 \\
\hline & Total & 40 & 447 & 114 & 58 \\
\hline
\end{tabular}

Hence, it is very difficult to quantify how many of the identified DDI were known by the physicians, but we assume that they were possibly unaware of the potential risk associated with certain combinations. To better quantify the clinical relevance of potential interacting drug combinations during hospital stay and 
to follow-up long enough after discharge to assess the outcomes of DDI even for those with a delayed onset. The clinical relevance of a DDI is often categorized into two dimensions, i.e., the expected 'severity' of a patient's physical reaction to DDI and the documentation. In fact, the clinical effects of any DDI, regardless of how well it is documented, do not occur in every patient or at the same level of intensity. They depend on patient-related factors that usually require individual assessment. However, our results showed that some patients would have suffered reactions from major DDI, but current clinical situation could not encourage us to excel our services. Hence, we feel that it would be helpful to include a physician in the study group in order to know the risk factor and management.

The potential adverse clinical consequences resulting from a specific interacting drug combination may sometime be counteracted by prescribing an additional drug. Moreover, the sequence of drug administration and patient related factors may be crucial for the occurrence of adverse effect, but generally, drug interaction programmes do not consider these aspects. All these factor could have resulted in the over estimation of the risk of DDI , so evaluation for actual adverse drug effects were done by screening the records of patients who had a major DDI pair prescribed.

To assess the clinical relevance of a DDI, it would be highly recommended to determine how often it appears in prescriptions. Additionally, DDI studies of clinical relevance are often carried out by a small group of volunteers, or arise from case series with specific patient or drugs. This study focused on identifying DDI caused by drugs prescribed and their clinical manifestation in patients based on Micromedex, DI text books, and journals. Other limitation of this study was closely related to information provided by different sources. Hence there may be possibilities of an overestimation of DDI in the whole sample. The major drug interacting combinations have been associated with clinically relevant reaction. Pharmaceutical care, electronic drug information, and pharmacotherapy evaluation of prescription could contribute to better patient health outcomes.

Check for DDI using Micromedex/DI text book/journals combined with clinical pharmacological experience and expertise as well as the knowledge of relevant patient related factors are the valuable and helpful tools to detect and deal with the clinical consequences of DDI's.

\section{Conclusion}

I. An evaluated $80.66 \%$ of drug-drug interactions from 242 prescriptions out of 300 studied from different wards was highest. Which warrant the immediate necessity of prescription audit by the competent pharmacist in the hospital to avoid jeopardy outcome.

II. About 40 (16.53\%) major drug-drug interactions have been reported out of 242 prescriptions indicate the urgent need in the modification of the prescription writing habit by the physicians with necessary update information.
III. In the present healthcare system there is no provision for analysis and documentation for either suffering or death. The pharmaceutical care is totally ignored hence it is very difficult to quantify the data for above parameters with relevance to drug-drug interactions or ADR.

IV. Based on our study at this juncture we would like to place on the record that, the prescriptions should be screened at least for 'major' DDI and drugs that are commonly involved in 'major' DDI, should be analyzed by a clinical pharmacist prior to drug dispensing. Patients should also be closely monitored for adverse drug reactions.

V. Our study concludes that, awareness about the drugdrug interactions among health professionals, computerized systems for prescription and drug information, as well as collaborative drug selection and pharmaceutical care are some of the possible solutions to the problem.

\section{General guidelines for the prevention of drug - drug interactions}

A. Never use any drug unless there is a good indication. If the patient is pregnant do not use a drug unless the need for it is imperative.

B. Ask if the patient is already taking other drugs including self-medication drugs; Interaction may occur.

C. Age may alter the metabolism or excretion of drugs, for which dosage adjustment may be required. Genetic factors may also be responsible for variations in metabolism, which should be considered.

D. Prescribe as few drugs as possible and give very clear instructions to the elderly or any patient who are likely to misunderstand complicated instructions.

E. When possible use a familiar drug than a new drug which may show unexpected events.

F. If any serious interaction is liable to occur, warn the patient to report it to the concerned authorities immediately.

\section{References}

1. Bahannan S, Hamid AA, Bahnassy A (1993) Noise level of dental handpieces and laboratory engines. J Prosthet Dent 70(4): 356-360.

2. Setcos JC, Mahyuddin A (1998) Noise levels encountered in dental clinical. cal and laboratory practice. Int J Prosthodont. 11(2): 150-157.

3. Szymanska J (2000) Work related noise hazards in the dental surgery. Ann Agric Environ Med 7(2): 67-70.

4. Kilpatrick HC (1981) Decibel ratings of dental office sounds. J Prosthet Dent 45(2): 175-178.

5. Clark WW, Bohne BA (1999) Effects of noise on hearing. JAMA 281(17): 1658-1659.

6. Wilson JD, Darby ML, Tolle SL, Sever JC (2002) Effects of occupational ultrasonic noise exposure on hearing of dental hygienists: a pilot study. J Dent Hyg 76(4): 262-269.

7. Trenter SC, Walmsley AD (2003) Ultrasonic dental scaler: associated hazards. J Clin Periodontol 30(2): 95-101. 
8. Kadankuppe S, Bhat PK, Jyothi C, Ramegowda C (2011) Assessment of noise levels of equipments used in the dental teaching institution, Bangalore. Indian J Dent Res 22(3): 424-431.

9. Singh S, Gambhir RS, Singh G, Sharma S, Kaur A, et al. (2012) Noise levels in a dental teaching institute-A matter of concern! J Clin Exp Dent 4(3): e141-e145.

10. Qsaibati L, Ibrahim O (2014) Noise levels of dental equipment used in dental college of Damascus University. Dent Res J (Isfahan) 11(6): 624630.
11. Wagner H (1985) How healthy are today's dentists? JADA 110: 17-24.

12. Miranda FJ (1985) Protect your hearing. Dental office sounds may be hazardous to your health. J Okla Dent Assoc 75(3): 38-39.

13. (1997) Prevention of noise induced hearing loss [monograph on the internet]. World Health Organization, Geneva.

\section{Your next submission with Juniper Publishers will reach you the below assets}

- Quality Editorial service

- Swift Peer Review

- Reprints availability

- E-prints Service

- Manuscript Podcast for convenient understanding

- Global attainment for your research

- Manuscript accessibility in different formats

( Pdf, E-pub, Full Text, Audio)

- Unceasing customer service

Track the below URL for one-step submission https://juniperpublishers.com/online-submission.php 